Clemson University

TigerPrints

Publications

Eugene T. Moore School of Education

$10-2014$

\title{
Taking Care: Understanding the Roles of Caregiver and Being Cared for in a Kindergarten Classroom
}

Cassie Quigley

Clemson University, cassieq@clemson.edu

Anna H. Hall

Clemson University, ah2@clemson.edu

Follow this and additional works at: https://tigerprints.clemson.edu/eugene_pubs

Part of the Education Commons

\section{Recommended Citation}

1. Quigley CF, Hall AH. Taking care: Understanding the roles of caregiver and being cared for in a kindergarten classroom. Journal of Early Childhood Research. 2016;14(2):181-195. doi:10.1177/ $1476718 \times 14548783$

This Article is brought to you for free and open access by the Eugene T. Moore School of Education at TigerPrints. It has been accepted for inclusion in Publications by an authorized administrator of TigerPrints. For more information, please contact kokeefe@clemson.edu. 
Taking Care: Understanding the roles of caregiver and being cared for in a kindergarten classroom

Cassie F. Quigley, corresponding author, email:cassieq@ clemson.edu and Anna Hall Assistant Professor, Teacher Education, Clemson University, 418 C Tillman Hall, Clemson, SC

\begin{abstract}
Despite concerns about the importance of teachers learning to care for their students, most teacher education programs do not utilize relational pedagogy and place little emphasis is placed on caring. In the current study, the authors used conversational interviews with one kindergarten teacher and photo-elicitation interviews with her twenty-two kindergarten students to explore ways in which this teacher in a public, all girls' school employed caring and how her students viewed being cared for. The authors utilized Noddings' (1984) work on the ethic of care to guide our project and the methodological approach is feministic. In this study, we discovered the ways this teacher cared and how that was translated for the students. Ultimately, we feel these ways of caring have implications for early childhood teacher preparation programs.
\end{abstract}




\section{Introduction}

Despite concerns of the importance of teachers learning to "care" for their students, most teacher education programs do not utilize relational pedagogy and place little emphasis on caring. The majority of programs spend their time focusing on content-related strategies to help students achieve academic learning objectives and ignore the importance of preparing teachers to provide caring and nurturing environments for their students (Brannen et al., 2003; Dahlberg, Moss, \& Pence, 2007) In this paper, we extend the work of Noddings (1995) and Brownlee's (2004) notions of relational pedagogy to provide insight to teacher educators about the art of “caring" by looking at the way one kindergarten teacher, Ms. $\mathrm{E}^{1}$, views caring and the ways in which her students respond to her caregiving.

During lunch Ms. E, a primary teacher of students age 5-6 in an all girls' public school ${ }^{2}$ in the Midwest of the US, looks at me and asks, "It is going well isn't it? " I respond, "It is- it is going very well," She sighs and states," It is amazing the difference." Ms. E is referring to her reduced class size, which was accomplished when the district added another primary class to reduce her class size from 34 to 22 . I see Ms. E scan the lunchroom and stop on a student who is saying, Shiya .Shiya is bothering Rava. Ms. E watches closely before getting up to intervene. She comes back and tells me "If I am honest with myself, I wanted [Shiya] to go to the new classroom. It would be easier, right? She is a challenge.” Ms. E looks me straight in the eyes, "But I knew she would just get yelled at the whole time. She is so smart and she needs the love. I will care for her." Over the past few weeks, I had observed how Shiya is often hugging Ms. E or

$1^{1}$ All names are pseudonyms to protect the identity of the students and teacher.

2 The school is single-sexed all girls primary (ages 5-10; grades K-5) in the Midwest of the United States. In the US, public schools are defined as receiving federal funding, complying to state and federal regulations and are free to constituents in their in which they are zoned. 
holding her hand. "When she is bored or lonely, she acts out," Ms. E continues. "My challenge is to make sure she is not either- bored or lonely."

Here, Ms. E admits Shiya is a challenging student and she even considered moving her to the other classroom. However, she describes a sense of responsibility towards Shiya in that she referred to Shiya as "my challenge," and wanted to keep her from getting "yelled-at" vs. getting what she needs "love." Here, Ms. E is attempting to generate a space where Shiya is not marginalized and where she can grow in a place where she is "neither bored nor lonely." As early childhood researchers, we immediately think of Nodding's (1984) notion of caring and ethical education when Ms. E states she will "care for her".

Noddings uses Mayeroff's (1971) definition of caring to mean, "To care for another person, in the most significant sense, is to help him grow and actualize himself." (p. 1) However, we extend this work by adding that scholars must concentrate on the one caring vs. the one cared for in order to extrapolate the ways in which caring leads to good pedagogy. Care is often weakly theorized in policy; therefore, there is little understanding about the connection between care and effective teaching (Boody, Cameron, \& Moss, 2005). Brannen \& Moss (2002) state: “care is one of those words widely used yet rarely defined" (p. 4). Because the conceptualization of care has changed and developed over time, the position of care in the classroom has been subject to changing practices influenced by the norms and cultures of different people, places, and time periods. Despite the evolution over time of notions of care (in respect to children), researchers agree that care has always served as a contextualized practice which shapes children's understandings of the world in which they live (Brannen \& Moss, 2002).

Researchers also posit that caring teachers must have a moral approach to solving problems (Bricheno \& Thornton, 2007; Kaga, Bennett, \& Moss, 2010; Narinasamy \& Mamat, 
2013); Teachers often take a moral approach to solving problems by situating themselves as close as possible to actual circumstances and assuming responsibility for actions (Harwood, Klopper, Osanyin, \& Vanderlee, 2012). Ms. E displayed a moral approach to solving problems when she took responsibility for Shiya and noted it was her job to keep Shiya engaged.

Noddings (1984) calls this moral approach to education, an ethic of caring. She posits as teachers (the one caring) teach students (the ones cared for), the student can learn to become the one caring for others. Other scholars disagree with Noddings and state this type of caring cannot be demanded or required of teachers. They contend teachers' work should be focused centrally on student learning objectives. In Harwood et al. (2012) most recent work, they remark the roles and responsibilities of early childhood educators are "vast and varied" (p. 2). In their crossnational exploration, the teachers described the emotional "caring" component of their teaching practice as being an inherent part of the profession. Through conversational interviews with the teacher and photo-elicitation interviews with the twenty-two primary students (girls; aged 5-6), we observed one primary teacher's classroom practices of caring and examine the ways the teacher and students viewed this caring. Thus, our research question was, "What are the ways in which one primary school teacher exhibits, promotes and models caring in her classroom and how do her students respond?"

\section{Relational Pedagogy}

Nodding's (1984) notion of caring and ethical education is situated within relational pedagogy, which supports the connection of relationships and theory as the foundation for good teaching practices. The roots of relational pedagogy can be traced to the Reggio Emilia area of Northern Italy where educators believe that "every child is creative and full of potential and has the desire and right to make meaning within a context of rich relationships" (Kim \& Darling, 2012, p.44). This approach values each child's individuality and focuses on the importance of the social 
environment. Instead of thinking about how much information can be transmitted to children during the school day, Reggio teachers focus on what happens in and in-between daily experiences; listening to the children and working together to gather thoughts and ideas (Parnell. 2011). Relational pedagogy builds on the work of Vygotsky's (1978) socio-cultural approach to cognitive development and Bronfenbrenner's Ecological Systems Theory (1979) by suggesting three practices that complement each other in creating a safe, interesting, and dynamic classroom environment (Brownlee, 2004). Relational pedagogy builds on the philosophy of the Reggio Emilia approach by suggesting three practices that complement each other in creating a safe, interesting, and dynamic classroom environment (Brownlee, 2004). These three practices are: 1. Showing respect to the student as knower; 2. Providing learning experiences that relate to students' own experience; 3 . Articulating and facilitating a constructivist approach to learning by emphasizing meaning making rather than knowledge accumulation. Through these parameters, relational pedagogy places the emphasis on the student and teacher, and not the content being taught. It is these very relationships that make relational pedagogy difficult to define because they are constantly changing by both the student and the teacher (Papatheodorou \& Moyles, 2009). As such, the learner has experiences and knowledge that become the viewpoint through which new knowledge and experiences are sifted and formalized. It is critical to identify relationships between experiences and knowledge that connect those relevant experiences in learning environments. In this way, we view relational pedagogy as an on-going, iterative relationship in which the teacher is seen as a guideone that facilitates knowledge rather than gives knowledge (Gold, 2005).

This role of facilitator instead of director is related to Belenky's (1986) connected teaching approach, which requires mutual respect between students, peers, and teachers in addition to a constructivist approach to learning. Respect between teachers and students allow the classroom to become a non-threatening environment for sharing ideas and constructing new 
knowledge. Learning in a constructivist setting is an emotional affair that invites children to reflect and experiment while teachers guide and support students' cognitive and emotional development. The second important practice of relational pedagogy is situating learning in students' experiences. When learning is situated within students' prior knowledge and interests, students become aware of the value of their own knowledge and their ability to construct new knowledge. During this practice, the teacher guides students in discovering links between new and prior knowledge while also demonstrating the value of students' ideas within the classroom environment (Baxter, 1993; Brownlee, 2004). Finally, relational pedagogy promotes on-going reflection. Teachers using critical reflection become more aware of their epistemological beliefs which provide a means for understanding how they choose their teaching practices and understand their students' learning. Reflection also provides opportunities for teachers to examine their personal theories as their levels of sophistication change and grow over time (Brownlee, 2004).

\section{Studies on Caring}

A variety of cultures embrace caring as the most effective way to teach, including the Chinese, Maori, and South Africans, among others (Sach, 2009). Darby (2005) studied student perceptions of teacher pedagogy as interpreted from a study focusing on students' experience of a middle school science classroom. The analysis centered on how students perceived the role of the teacher's pedagogy as related to their learning. Overwhelmingly, students pronounced their learning to be enhanced when they felt the teachers cared about them. Doyle (2006) contends caring comes naturally to teachers, and clearly natural caring occurs in classrooms. However, as Papatheodorou and Moyles (2009) argue, caring and relational pedagogy are highly specialized and skilful tasks that require training for non-parental caregivers.

As we conceptualize "to care" and "be cared for", we understand the two parties are interwoven. For example, when a teacher cares for a student, the student becomes the one being 
cared for. This ethic of caring is reciprocal. Similarly, Moss and Brennan (2003) use the phrase "care and children" instead of "care of children" to denote the active role children have in caring. As such, Peters (2009) studied this reciprocal relationship in an early childhood classroom in New Zealand. She examined the implementation of a care-based curriculum, Te Whariki. Throughout her research she discovered there was an emphasis on an orientation towards learning goals vs. performance goals. The students were guided towards specific dispositions (courage, curiosity, trust, playfulness, perseverance, confidence, and responsibility) rather than content-driven outcomes. That said, there were curriculum documents that guided what educators typically recognize as learning, but the assessments were designed to construct and foster learning. Carpenter, McMurchy-Pilkington and Sutherland (2002) corroborated these results in a similar setting.

Interestingly, these results are not unique to settings in New Zealand. Klem and Connell (2004) found enhanced academic performance and improved attendance records when teachers cared about their students in their large-scale and longitudinal data in elementary, middle, and secondary schools. Through their study, which analysed the experience of the teachers, engagement of students, and outcomes of students, they found when students perceived teachers cared about them they were more engaged in school, more likely to attend school, and scored better on achievement tests. These results were also achieved when the teacher was a different ethnicity from the students, as is often the case in urban schools in the US (Hawk, Cowley, Hill, $\&$ Sutherland, 2002)

As this study is examining the contribution of caring in context, we must return to the realities of the classroom. Repeatedly, as educators, we hear the words, " $21^{\text {st }}$ century learners." We need to consider the type of $21^{\text {st }}$ century learners we are interested in: those that achieve well 
on standardized tests or those who engage with knowledge in a way that encourages responsiveness and relevance. As such it is helpful to consider Giroux's (2003)argument that education in the US is unproductively focused on decontextualized skill sets. Thus, if we examine the pedagogy of the latter, it may be viewed as "critical practices in which students learn to be attentive and responsible to the narratives of others" (Giroux, 2003, p. 87). At the same time, the authors recognize building relationships without improved student learning does not constitute good pedagogy.

\section{The study}

This study explored the ways in which one primary teacher discussed caring and how her students viewed being cared for. Because we utilized Noddings' work on the ethic of care to guide our project, the methodological approach is feministic. Specifically, we employ the feminist oral histories approach (Anderson \& Jack, 1991) in order to understand what was occurring in this kindergarten classroom. The feminist embrace of oral history emerged from, “a recognition that traditional sources have often neglected the lives of women, and that oral history offered a means of integrating women into historical scholarship, even contesting the reigning definitions of social, economic and political importance that obscured women's lives." (Sangster, 1994).

\section{Context}

The context of this study is an all-girls public science academy with a focus on one of the two kindergarten classrooms. The school became a single-sex school in 2002 after they were forced to re-structure due to low state test scores. The school and the community decided to become a science-focused academy to de-bunk some of the gendered stereotypes regarding girls' science ability. Since 2008 the school has met AYP (Adequate Yearly Progress; a federal 
requirement of the No Child Left Behind Act) and continues to be a "choice" school in the state.

The majority of the 433 girls at this school live in one of the two public housing developments within a four block radius of the school. The student population of the school is $99 \%$ Black and $1 \%$ Multiracial. Additionally, $88 \%$ of the students qualify for free lunch. The gendered academy is in its sixth year. For the past three years, the school has made Adequate Yearly Progress for reading and math in all grade levels. This study focuses on one primary classroom. The teacher, Ms. E, has taught kindergarten for 19 years and at McCullough since it opened its doors in 2004. There were 32 African American girls in her classroom through September however the classroom was reduced to 22 girls to comply with state laws. All of the parents provided written consent for their daughters to participate in the study. Each of the girls provided verbal assent. Eighteen of the girls were six years and four of the girls were five years old.

Additionally, we sought a methodology that understands interviewing as a problematic activity - particularly when interviewing very young girls as we did. It is for this reason we chose the data source, photo-talks (Serriere 2010) (see below for description) and the Listening Guide data analysis approach (Anderson and Jack 1991) as a way to complement this feminist methodology.

\section{Data Sources}

There are two primary sources and two secondary data sources for this study. Each source is described below.

Photo-talk interviews. We chose the use of a methodological tool called photo-talks Photo-talk has been used in memory recall for very young children; this also provides subjects an opportunity to explain and reflect upon moments captured by the camera (Serriere, 2010). By 
capturing the still visual moments of our interpretation and creating a slideshow of a series of moments, we allowed the students to stop the slideshow at any time and explain their perceptions of the moment (Author 1, 2012).

We followed a daily procedure in doing photo-talks. After the morning's observations and photographs were completed, we uploaded them to my laptop and invited over one girl at a time to look at all the photographs in a slideshow format. Typically this occurred during science clean-up time or quiet time after lunch. Most of the time the girls wanted to participate, however there were also times when the girls sat down next to Author 1, looked at the pictures and asked not to talk. Depending on the duration (usually between 3-5 minutes) of the interviews, Author 1 dialogued with 1-10 girls per day. The photo-talks were audio taped creating another layer of data to the original video recordings of the scenes captured by the photographs (Author 1, 2012). Using multiple modes for communicating experience and meaning, provide additional information on themes and concepts. It provides information one data-collection strategy might not have generated. All data have what Banks (2001)referred to as internal and external narratives. In our data, the conversations during the interviews (internal voice) complement the photographs that provide the social context in which the data was created (external voice). Although data cannot replace the experience itself, these two voices enhance the data as they are brought together (Becker, 2002). A total of 136 interviews were conducted over 6 months. Author 1 tried to be consistent about the frequency of interviews across time and participants.

Teacher interviews. Author 1 interviewed Ms. E, the kindergarten teacher, throughout the study. Usually, these interviews took place in informal spaces such as the lunchroom or the hallway. The interviews were semi-structured except for the life history interview, which occurred at the beginning of the study. The purpose of the interviews was to understand more 
fully some of the teacher's pedagogical techniques and rationales behind her actions. A total of 15 interviews were conducted over six months. Some of the interviews were longer in duration (30-45 minutes) however; most others were shorter (5-8 minutes). The informal interviews were not recorded, but the reconstructed notes were member-checked by Ms. E.

\section{Data Analysis}

In order to understand the ways in which the teacher and the students viewed caring in the classroom, we employed a Listening Guide data analysis approach by utilizing Noddings' notions of care (one-caring for, one being cared for, and mutuality of caring). Listening Guide is a voice-centred approach that examines the interplay between societies understandings of gender with the participants' actual experiences (Beauboeuf-Lanfontant, 2008). Voice-centered scholarship places the focus on ways in which individuals speak. Previously, Listening Guide has been used to understand aspects of gender socialization (Tolman, 2002) anger in girls (Brown, 1998) and boys' friendships (Chu, 2005). Because we are seeking to understand the extent to which caring was a part of this classroom for young girls, we felt this analysis tool was appropriate for its attention on power, race, and class in society.

We followed Beauboef-Lanfontant's (2008) recommendation for Listening Guide analysis. This includes reading the transcripts multiple times while looking for different meaning during each read. The first read is a reflexive reading that is guided by one's theoretical leaning (here, Ethics of Care and Relational pedagogy). Thus, we utilized a pre-existing coding scheme provided to us by Nodding' notions of caring: ideas of one being cared for, one caring, and when both participants were caring for each other, to guide this primary analysis. During this first reflexive read, we analysed the participants' language and the researchers responses (the researchers responses being the reflexive component). In our study, we were interested in the 
ways in which the teacher exhibited care and the reactions to that care in the learning environment. This included examining repeated themes the teacher and students used during their interviews and following the repeated themes with an examination of "I" statements. Thus, when a student or Ms. E talked about herself in the first person in relation to caring, we analysed those conversations. For example, when Stella mentions, "I can help my friends in my class by listening to them." We noted this conversation and analysed it using the coding scheme. Then, we read and re-read the identified sections, this time focusing on the girls' and the teacher's talk of self. We noted "I" statements as well as times in which the participants referenced the self in less direct ways, such as "you" or "we". In this way, we accounted for moments in which the students or Ms. E talked about the ways others cared for them or their interpretations on reactions of their caring. For example, when Sharon stated, "When Ms. E shows us how to do things by ourselves and shows us how to help others we learn. Like when she taught us how to put my coat on the upside down way, we taught Tessa to do it." In this section, we analysed Sharon's use of the plural form "us" and "we"

During the secondary analysis, we focused on the notion of caring to explore further what subtleties were present. In this way, we were seeking to extrapolate the nuances that were occurring during these times. Then, in the final round of data analysis, we reviewed these stances of the self with regard to both the individuals' ideas of caring and its relationship to learning.

\section{Results}

Based on our Listening Guide analysis, we constructed three major themes from the notions of caring: one being cared for, one caring, and mutuality of caring. Each of the themes and the sub-themes will be described below. In our results section, we outline three different notions of caring. The first two are unidirectional in terms of caring (one caring and one cared 
for) however; this is not to say that we view caring as one-sided. Instead, we view these notions as interrelated and connected and in the third theme, mutuality of caring, we describe this dialogical relationship. The goal of this work is to provide examples of caring as it relates to student learning, thus, the first two themes are focused on the teacher-actions and ways in which the teacher cares in her classroom and how the students view these actions. We do acknowledge that care is multidirectional — students are often the carers, teachers are often cared for, and children care for each other in the classroom. However, the scope of this study was the interaction between teacher and her students to extrapolate the ways in which teachers can promote a "care" environment.

\section{One caring}

In this theme, one person describes or is named as the caregiver. Here, this person was Ms. E. As such, there are two sub-themes that describe being the caregiver in this classroom: responsibility and seeing student as knower.

Responsibility. Similarly, during a teacher interview, Ms. E describes caring as a teacher's responsibility. Interestingly, Ms. E remarks because of her care-giving role, it is one of the reasons she became a teacher. However she also describes good teaching as more complex than that:

Ms. E: Well, it started off when I was a little girl. I just loved to - well, my sister wanted to be the teacher all the time. And I was the younger one, so of course I had to listen and do exactly what she wanted me to do. And so we used to play "school" in the garage in our house. And I think I came to liking that. But I always wanted to be that leader role and I never got an opportunity to. And I was always taking care of everyone. At first it seemed natural but then when I went to school there was a lot more to it. I made a lot of mistakes in those first years of teaching. But then I took this class- in my Masters that focused on culture. I got better at teaching. I learned how to make things meaningful. And caring-caring and not giving up is a big part of it-really it is your job.

In this interview, Ms. E simply stated caring "is your job" as a teacher. She views it as responsibility of the teacher to care and not give up. Additionally, she described playing school 
in her garage at school was a formative experience which helped lead to her career in teaching. That said she understands that "there was a lot more to it." She modestly admits, that she is a leader in the school. She is a member of every task force initiated by the district or school such as the School Improvement Plan, the School Renovation Committee, and the Technology Committee. She leads professional development sessions at the school and attends professional development programs offered to her throughout the school year and summer. When I ask her about her success she boils it down to one thing, "being involved with the community." Several people argue that caring and relational pedagogy come naturally, and of course caring can come naturally. However, as Papatheodorou and Moyles (2009) argue that for non-parental caregivers it is a highly specialized and skilful task that requires training. Although Ms. E's natural ability to caring led her to teaching, she felt it was not until she continued her education and learned about culturally-relevant pedagogy that, "I got better." She continues, "I learned that there were theories that aligned to what I wanted to see in my classroom. What I didn't know was called inquiry-based learning, turns out to provide a space for the girls to learn and explore. I think it is a teacher's responsibility to discover these types of practices."

Student as knower. In addition to viewing caring as her responsibility, Ms. E also views the students as knowers. In this way, she has respect for her students in that students are a central part of knowledge construction and as such, are knowers. Below, during a photo-talk interview, Rava describes a time when Ms. E viewed the students as knowers by allowing them to veer from the planned curriculum and observe a cricket that was hopping on the carpet.

\footnotetext{
Interviewer: Is that the cricket that she's holding? Student: Yes.

I: $\quad$ Yeah. And where did you find that cricket?

S: $\quad$ It was on the floor. It gots six legs and it was crawling, and Ms. E was - it was on the rug and Ms. E tried to get it. Then Ms. E tried to get it, then Ms. E did get it, but it was still hopping.

I: $\quad$ It was still hopping? That's funny.

S: $\quad$ We saw Ms. E hold up that cup and we saw the cricket in there, and we was passing the
} 


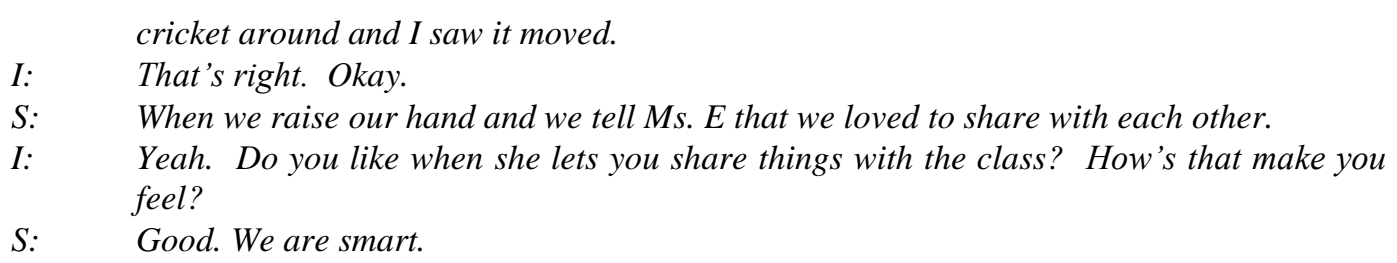

Using this asset-based approach to teaching, she allows students to break from her planned activity to explore a cricket that was crawling on the floor. The students commented on this simple activity of capturing a cricket and observing it in a cup for months to come. Ms. E passed the cup around asking the girls to observe and make comments on the cricket. As such, Rava describes this event as making her feel good and "smart." When positioning students in charge of their learning, these simple explorations can be very powerful and empowering for students.

\section{One being cared for}

In this theme, one being cared for, the students describe being cared for. For example, the students describe the ways Ms. E is able to connect their previous or relevant experiences to their learning. With this personal connection, the students felt cared for. Additionally, the students described how learning occurred when they felt they were cared for. In this way, the students described an interplay of learning in that learning and caring were interconnected. As such, there are two sub-themes: using student experiences and interplay of learning. Each subtheme will be described below.

Using student experiences. Students described receiving care as an experience connected to their learning and often recalled learning opportunities provided by Ms. E that related to their own experiences. Below Macy describes being cared for in a way that is related to her own experience:

I: $\quad$ Okay. And here you were describing the pictures to Rava, and you were telling her about your story. 


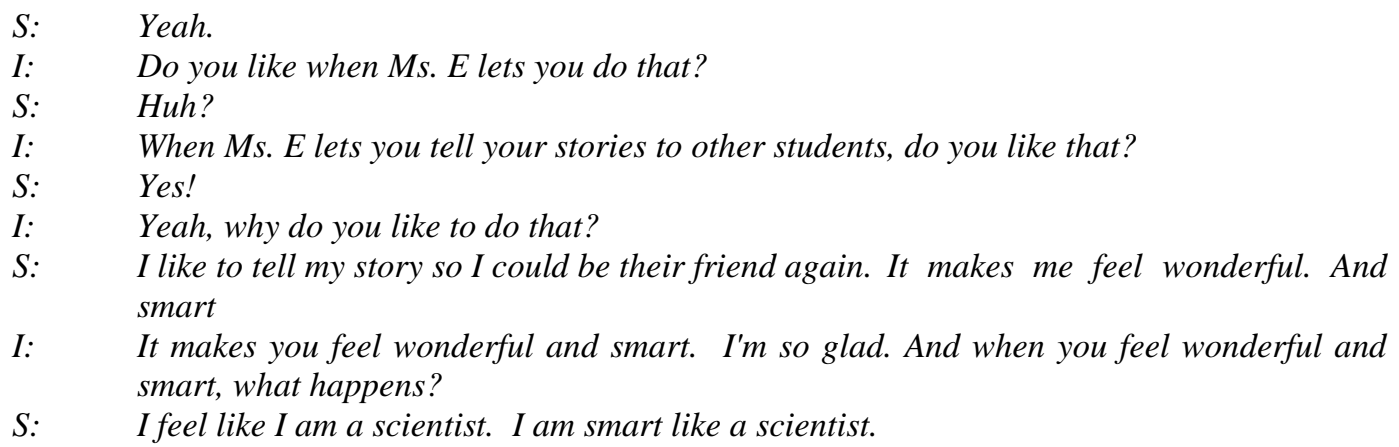

Relating to the students' own experience is one of the major components of relational pedagogy. Here, Macy remarks that being able to tell her stories to the class helps her to make friends and feel "wonderful and smart." She even connects these feelings to becoming a scientist when she states, "feel like I am a scientist. I am smart like a scientist."

Interplay of learning. In early childhood classrooms, learning often occurs when caring occurs. This interplay of learner between the student and teacher is often described when the student feels cared for. We view this notion of being the one caring as connected to dialogue. Below, Shiya describes how learning occurred for her, which was about the relationship between Ms. E and Shiya:

I: $\quad$ Do you know what that's called?

S: $\quad$ Um-I don't know. But it goes up when it is sunny. And then when it gets snowy it's gonna go down, down, down.

I: $\quad$ When it gets snowy it goes down. When it gets sunny it goes up.

S: $\quad$ But when it's gonna go way up? Summertime? Or like when we aren't in school with Ms. E anymore. I don't want it to be summertime. I love Ms. E. She loves me. She helps me learn. Really I only learn with her.

During this conversation, one hears the scientific discourse spoken when Shiya describes the way a thermometer works in her own words. In this moment, Shiya is able to blend her home and school discourse to make sense of the scientific tool, the thermometer. Then she considers a time when she will not be in Ms. E's classroom, which causes her to describe her relationship with Ms. E and says, "I love Ms. E. She loves me. She helps me learn. Really I only learn with her.” 
She even suggests this is the reason she is learning. For Shiya, learning and love are interconnected.

\section{Mutuality of caring}

In many cases, the students described caring for others or caring for Ms. E at the same time they felt cared for. This mutuality of caring demonstrates how comfortable the girls were feeling in their learning space. Noted during these times of mutual caring were an individual's contribution to a collective task and building a community.

Individual's contribution to a collective task. When the girls described caring and being cared for, they often did so in a way in which they were individually contributing to the group in some way. For example, Anaria, a child who has trouble articulating her thoughts and making friends, describes a time when she contributed to the class observation table. The observation table began after a field trip to a state park near a beach in which the ranger allowed the girls to take a seashell or a rock from the beach and bring it home. Over the next few weeks, different girls began bringing in different objects to observe and more importantly, according to the girls, share their objects with their friends. Most objects were closely tied to the changing leaves discussions they were having — giant Maple leaves with vibrant colours were very popular but so were acorns, and bits of bark, particularly if they had some sort of unusual marks such as holes or moss growing on them. Then came the influx of twigs, branches, berries, and rocks.

S: "Ooh, here is a picture of me and my bark."

I: "Why did you bring in the bark today?"

S: "Cause I wanted my friends to like it and I thought they was gonna be happy at me and they were".

Indeed, the girls do respond positively towards Anaria as she brings in objects and often has interesting stories that fit with her objects - a cracked acorn that could have cracked from a squirrel trying to eat it, a bright red leaf is so bright the girls have trouble believing that it was 
once green until Anaria points at the very tiny dots of green still left in the leaf, and a brittle twig she found on the steps of her grandma's house that she inferred was dead because someone stepped on it. Throughout the year, the girls continually brought in items to observe together and many students mentioned this is an activity that made them feel cared for.

Building Community. Similarly to contributing to a collective task, the girls often described that they were building a community during times of mutual caring. Below T'Yael describes several instances when she understood that she was a part of a community and needed to share with the others in her class:

I: $\quad$ Did you want to tell me something else?

S: $\quad$ Yeah. Well, we was lookin' over there, and Brianna was raisin' her hand, but I hold my hand down.

I: $\quad$ Why do you hold your hand down?

S: $\quad$ Well, Brianna wanted to take a, Brianna wanted take the thing first, so I put my hand down.

I: $\quad$ Oh, okay. So, you were letting her have a turn. Okay, you were sharing?

S: $\quad$ Ms. E says we share because we are a family

At the beginning of the interview, T'Yael states that she put her hand down to "share because we are a family." Even though she felt she had something to contribute to the class discussion, she wanted to give Brianna a chance to share. She is beginning to understand that she is a part of a larger community-her class. For her, that means allowing others to speak even when she has something to say. Noddings notes that this cognition of others and allowing them to be a part of the community is critical to the mutuality of caring. In this instance, T'Yael describes the class as a "family."

\section{Discussion}

It seems obvious in an everyday sense why teacher educators should be interested in caring. However, for the last 20 years, educational researchers continue to call for more caring in schools (Grumet, 1988; Noddings, 2004; Papatheodorou, 2009). Perhaps it is all the attention on 
student achievement gains that has left the educational field with the feeling our classrooms are sterile environments instead of places where relationships are built. Or perhaps it is the push of a business model for education with its notion of students as "consumers" and educators as "producers" of knowledge - that there is little time for caring (Palmer 2007). Regardless of the reason, early childhood researchers continually document the critical ways in which teachers must care for their students if their students are to learn.

During this study, we were fortunate to document one teacher demonstrating the three key practices of relational pedagogy: 1 . Showing respect to the student as knower; 2 . Providing learning experiences that relate to students' own experience; 3. Articulating and facilitating a constructivist approach to learning by emphasizing meaning-making rather than knowledge accumulation. (Brownlee, 2004). We were also able to observe how her students responded to this caring environment. Although Ms. E does not mention modelling caring for her students, we noted moments in which the students commented there was a mutuality of caring and that they were aware that Ms. E cared for them. These shared feelings of caring illustrate the practice of mutual respect within Ms. E's classroom. When caring for her students, Ms. E saw this as her responsibility and described it as the teacher's job to care. Brooker (2007) emphasizes teacher's responsibility for caring when she reflected, "Teachers now have collective responsibility...for all aspects of a child's, and the family's, well- being" (p. 12). Noddings (1995) described this responsibility during her discussion of modelling caring for students — she remarked that even though teachers should model this behaviour for her students, they should be aware that their primary responsibility was caring for her students. She warned teachers that modelling should never detract from the action of caring and that it should focus on self-reflection. She cautions the shift of focus however well intended, "has its dangers and carried too far, it actually moves 
us away from caring.” (1995, p. 140) Here, Ms. E is centrally focused on caring for her students. Papathedorou (2009) hopes that as teachers like Ms. E continue to view caring as a responsibility then, "the concepts and reality behind relational pedagogy will become more prominent." (location 586).

Moreover, we learned that in a classroom of caring, there was a mutuality of caring in which the individual's input contributed to a collective task and community building in the classroom. As caring is a process that shifts from the caregiver to the one being cared the lines of caring are often blurred. Thus, it often becomes difficult to label who is caring and who is cared for. Instead, these roles often swing back and forth. In this classroom, this mutuality of caring was documented when students "shared" or "allowed someone else to talk." Even though these roles are not static, teachers often take the role of being the central caregivers. Noddings comments that teachers often need to feel cared for in order to continue caring-calling it the reward for their hard work. Although she cautions this mutuality is not necessary for an environment of care, it is often the result of modelling the action of caring for her students. Students learn the behaviour from their teachers and repeat it. Early childhood educators need to possess relational understandings for mutuality of caring to occur in our classrooms because "without opportunities to develop the capacity for relational knowing, teachers and teacher educators will never be able to teach their students to develop such capacities" (Gallego, Hollingsworth, \& Whitenack, 2001).

In addition, when Ms. E was caring for her students, she was situating learning in students' experiences. She intentionally positioned her students as knowers in her classrooms. Interestingly, the idea of caring by positioning students as knowers mimics Freire's ideas (1970) of caring and dialogue. Dialogue, according to Freire (1970), is open-ended and indeterminate. It 
is a conversation in which neither party knows the outcome at the onset. It is joint effort of understanding, learning, empathy, and appreciation for each other, in that "continuing dialogue builds up a substantial knowledge of one another that serves and guides our responses" (Noddings, 1992, p. 23). Ms. E has a strong desire for the girls to succeed, which is tied to the relational pedagogical components present in her teaching (Brownlee, Purdie, \& Boulton-Lewis, 2001). These include incorporating discourses, dialoguing with her students, viewing the students as knowers-all components of caring for her students. We discovered the students often described being cared for in the classroom as times when their experiences were incorporated in the classroom. As mentioned above, sometimes this was in the form of telling stories. The girls commented that they felt "wonderful and smart" during these times. By incorporating the girls' experiences, Ms. E created a space in which the girls were learning while having their ideas and knowledge validated in the process through being cared for and having a space where they could construct and share this knowledge. When Ms. E incorporates their experiences through story-telling, she is validating their knowledge and experiences.

Finally, when she was caring for her students, she was facilitating a constructivist perspective of knowing and learning by fostering interplay of learning. The interplay of learning was dialogical and demonstrates how learning is interactive and shifting. Learning is a dynamic process that shifts from students to teachers through dialogue. For learning to occur, this interplay needs to occur. Both Freire (1970) and Noddings (2001) stress the importance of caring as the foundation of this interplay. Shiya stated, "really I only learn with her" because "she loves me. I love her." In this way, the learning that was made possible because she felt loved. Freire (1998) argues for rooting education in the interplay of the learner and teacher and calls on educators to be engaged in "acts of love" (p. 38). This shifts the focus from teachers as 
technicians towards teachers as caregivers. If we can teach students to view teaching as a personal activity in combination with technical skills (i.e. communication, management, organization), we can contribute to the development of a theory of teaching practice that works towards intuitive teaching and incorporates professional judgement (Carr, 2001). This action is reminiscent of Freire's (1998) interplay of learner and teacher. He describes this interplay as of paramount importance especially when learners and teachers come from different positions in order to create educational experiences they will both recognize. This interplay of learning is dialogical, relational, and produced in action (Bartlett, 2005). Freire (1970) even suggested that this interplay is related to understanding the home discourse of students. Moreover, Freire (1970) emphasizes love in his explanation of the dialogical process when he stated, "Dialogue cannot exist ... in the absence of a profound love for the world and for [human beings] ...." (p. 77-78) Many researchers comment on the importance for understanding and creating a community in classrooms, particularly for urban areas. For example, Palmer (2007) remarks that we can only really know a community by being a part of it. Here, Ms. E. builds a community with her girls when they are caring-for and being-cared for. Throughout this study we noted three major components of Noddings' care model: modelling, dialogue and confirmation. We did not see the fourth component, practice. This might be because Ms. E did not view caring as pedagogical action—she viewed it as "her job". Additionally, as a master teacher of over 30 years, it might have been difficult for her to describe how she learned to care. That being said, Noddings (1992) states that teachers must practice caring. Learning to care is a skill that needs to be practiced and Noddings (1992) argued, "we need to provide opportunities for them to gain skills in care giving and more important to develop the characteristic attitudes of caregivers" (pp. 23-24). While Noddings (1992) argues that practice can and should occur in the homes and 
schools, we contend that as teacher educators we can also provide practice for future teachers by incorporating these ideas into preservice education.

\section{Implications}

One implication of this study is for future work to develop specific strategies for early childhood educators utilizing the examples discussed in this paper. Baxter Magolda (1993) describes characteristics of extended relational pedagogy that can guide us in preparing future teachers. Teacher education programs can teach and model the following strategies during methods courses and field placements: (1) setting up a non-threatening learning environment, (2) making links to children's prior knowledge to validate students as constructors of knowledge, (3) allowing students to collaborate to exchange viewpoints, (4) focusing on both the social and cognitive dimensions of learning, (5) modelling constructivist teaching, (6) allowing students to develop personal meaning and connect learning to their own experiences, (7) creating a classroom community with teacher as co-learner, (8) encouraging dialogue and critical thinking, and (9) encouraging students to examine the contradictions of their current beliefs (Adapted from Baxter Magolda, 1993). In addition, this study implies that weaving research and strategies related to relational pedagogy throughout all of the courses in an early childhood teacher education program would benefit not only future teachers, but more importantly all of the children that they will soon teach.

\section{Conclusion}

Strong policy initiatives are emanating from the federal government to effect change in the US. This rhetoric needs examining to avoid sending conflicting messages to early childhood educators. The continual shift of a national standards-driven agenda, regardless of children's experiences and circumstances, is in conflict with individual education plans that the government 
simultaneously touts (Raider-Roth, 2005). This study attempts to expand the research on early childhood education research with particular attention on developing the notion towards a praxis of caring. We seek to understand the ways in which relational pedagogy can be enacted and in the types of school spaces can occur through this notion of caring. Noddings (1992) continues describing that most schools are in a crisis of caring:

Both students and teachers are brutally attacked verbally and physically. Clearly, the schools are not often places where caring is fulfilled, but it is not always the failure of teachers that cause the lapse of caring. Many urban teachers are suffering symptoms of battle fatigue and "burn-out". No matter what they do, it seems, their efforts are not perceived as caring. They themselves are perceived, instead, as the enemy, as natural targets for resistance. (Location 2700)

Because of this crisis of caring, the caregiver is a necessary model for the one caring. The cycle continues as the one caring receives care and continues to give care to others. Noddings (1992) recommends schools and teaching be redesigned so caring has a chance to be fostered. She calls to "unlock our doors and disarm our security guards." (location 2710) We take this notion a step further - if caring is added to the robust literature on teacher education and as teacher educators we teach ways to care, teachers will have specific pedagogical strategies to create an environment that is supportive of an ethic of care which is foundational to learning. 


\section{References}

Anderson, K., \& Jack, D. C. (1991). Learning to listen: Interview techniques and analysis. In S. Gluck, \& D. Patai (Eds.), Women's words: The feminist practice of oral history (pp. 11-25). New York: Routledge.

Banks, M. (2001). Visual methods in social research Sage.

Bartlett, L. (2005). Dialogue, knowledge, and teacher-student relations: Freirean pedagogy in theory and practice. Comparative Education Review, 49(3), 344-364.

Baxter, M. (1993). The convergence of rational and interpersonal knowing in young adults' epistemological development. Paper Presented at the Annual Meeting of the American Research Association Atlanta, GA.

Beauboeuf-Lanfontant, T. (2008). Listening past the lies that make us sick:A voice-centered analysis of strength and depression among black women. Qualitative Sociology, 31(391-406)

Becker, H. S. (2002). Visual evidence: A seventh man, the specified generalization, and the work of the reader. Visual Studies, 17(1), 3-11.

Belenky, M., Clinchy, B., Goldberger, N., \& Tarule, J. (1986). Women's ways of knowing: The development of self, voice, and mind. New York: BasicBooks.

Boody, J., Cameron, C., \& Moss, P. (2005). Care work: Present and future. New York: Routledge.

Brannen, J., Moss, P., Aggleton, P., Cameron, C., Chalmers, H., Heptinstall, E., . . Petrie, P. (2003). Rethinking children's care Open University Press Buckingham.

Bricheno, P., \& Thornton, M. (2007). Role model, hero or champion? children's views concerning role models. Educational Research, 49(4), 383.

Bronfenbrenner, U. (1979). The ecology of human development. Cambridge, MA: Harvard University Press. 
Brooker, L. (2007). Changing the landscape of early childhood. In J. Moyles (Ed.), EArly years foundations. Meeting the challenge. Maidenhead: Open University Press.

Brown, L. (1998). Raising their voices: The politics of girls' anger. Cambridge, MA: Harvard University Press.

Brownlee, J. (2004). Teacher education students' epistemological beliefs developing a relational model of teaching. Research in Education, 72, 1-17.

Brownlee, J., Purdie, N., \& Boulton-Lewis, G. (2001). Changing epistemological beliefs in pre-service teacher education students. Teaching in Higher Education, 6(2), 247-268.

Carpenter, V. M., McMurchy-Pilkington, C., \& Sutherland, S. (2002). Kaiako toa: Highly successful teachers in low decile schools. Set, 2(4-8)

Carr, M. (2001). Assessment in early childhood settings. London: Paul Chapman.

Chu, J. (2005). Adolescent boys' friendship and peer group culture. New Directions for Child and Adolescent Development, 107, 7-22.

Dahlberg, G., Moss, P., \& Pence, A. (2007). Beyond quality in early childhood education and care: Languages of evaluation Taylor \& Francis.

Darby, L. (2005). Science students' perceptions of engaging pedagogy. Research in Science Education, $35,425-445$.

Doyle, J. (2006). Postmodernism and the approach of writing in irish primary education. Journal of Early Childhood Literacy, 6(2), 123-143.

Freire, P. (1970). Pedagogy of the oppressed. New York: Continuum.

Freire, P. (1998). Pedagogy of the oppressed (20th Anniversary Edition ed.). New York: Continuum Publishing.

Gallego, M. A., Hollingsworth, S., \& Whitenack, D. A. (2001). Relational knowing in the reform of educational cultures. Teachers College Record, 13(2), 240-266.

Giroux, H. A. (2003). The abandoned generation: Democracy beyond the culture of fear. Basingtoke: Palgrave Macmillan. 
Gold, L. (2005). An introduction to relational pedagogy: Relationships at the heart of learning. Paper Presented at the Third Internationl Conference on New Directions in Humanities, Cambrige, UK. , August 2-5.

Grumet, M. (1988). Bitter milk: Women and teaching. Amherst: University of Massachusetts.

Harwood, D., Klopper, A., Osanyin, A., \& Vanderlee, M. (2012). 'It's more than care': Early childhood educators' concepts of professionalism. Early Years, 1-14. doi:10.1080/09575146.2012.667394

Hawk, K., Cowley, E. T., Hill, J., \& Sutherland, S. (2002). The importance of the teacher/student relationship for maori and pasifica students. Set, 3, 44-49.

Kaga, Y., Bennett, J., \& Moss, P. (2010). Caring and learning together: A cross-national study on the integration of early childhood care and education within education. Paris, UNESCO, 26, 9.

Klem, A. M., \& Connell, J. P. (2004). Relationships matter: Linking teacher support to student engagement and achievement. The Journal of School Health, 74(7), 262-273.

Mayeroff, M. (1971). On caring. New York: Harper and Row.

Narinasamy, I., \& Mamat, W. H. W. (2013). Caring teacher in developing empathy in moral education. The Malaysian Online Journal of Educational Science,

Nodding, N. (1995). Care and moral education. In W. Kohli (Ed.), Critical conversations in philosophy of education (pp. 137-148). New York: Routledge.

Noddings, N. (1984). Caring: A feminine approach to ethics and moral education (2nd edition ed.). Berkeley, CA: University of California Press.

Noddings, N. (2001). The care tradition: Beyond 'add women and stir'. Theory into Practice, 40(1), 29.

Noddings, N. (2004). High stakes testing: Why? Theory and Research in Education, 2, 263-269.

Palmer, P., J. (2007). The courage to teacher: Exploring the inner landscape of a teacher's life (Tenth Anniversary Edition ed.). San Francisco: Jossey-Bass.

Papatheodorou, T. (2009). Exploring relational pedagogy. In T. Papatheodorou, \& J. Moyles (Eds.), Learning together in the early years: Exploring relational pedagogy (). London: Routledge. 
Papatheodorou, T., \& Moyles, J. (Eds.)(2009). Learning together in the early years: Exploring relational pedagogy. London: Routledge.

Peters, S. (2009). Resposive, reciporical relationships: The heart ofTe wharikicurriculum. In T. Papatheodorou, \& J. Moyles (Eds.), Learning togethers in the early years: Exploring relational pedagogy. London: Routledge.

Raider-Roth, M. (2005). Trusting what you know: The high stakes of classroom relationships. ERIC.

Sach, J. (2009). Nuturing inspiration. In T. Papatheodorou, \& J. Moyles (Eds.), Learning together in the early years, exploring relational pedagogy (). London: Routledge.

Sangster, J. (1994). Telling our stories: Feminist debates and the use of oral history. Women's History Review, 3(1), 5-28. doi:10.1080/09612029400200046

Serriere, S. (2010). Carpettime democracy: Digital photography and social consciousness in the early childhood classroom. The Social Studies, 102(1), 60-68.

Tolman, D. (2002). Dilemmas of desire: Teenage girls talk about sexuality. Cambridge, MA: Harvard University Press.

Vygotsky, L. S. (1978). Mind in society: The development of higher psychological processes. In M. Cole, V. John-Steiner, S. Scribner \& E. Souberman (Eds). Cambridge, MA: Harvard University Press. 